\title{
Descrição de eventos de letramento no primeiro ano de um curso de graduação: plágio, paráfrase e ensino de escrita acadêmica
}

\section{Literacy events description on the first year of a Brazilian undergraduate course: plagiarism, paraphrase and academic writing teaching}

Márcia Sipavicius Seide *

\begin{abstract}
RESUMO: Este estudo de caso descreve eventos de letramentos ocorridos ao longo de uma disciplina de primeiro ano de um curso de Licenciatura em Letras. Os eventos abrangem os que foram promovidos por iniciativa do professor da disciplina e os criados como resposta às necessidades de aprendizagem dos alunos. Entre essas, destacou-se a de superar o uso do plágio como estratégia de escrita. Fundamentam o estudo a concepção de ensino centrada nas necessidades dos alunos e a abordagem de ensino de escrita acadêmica baseada nos letramentos acadêmicos (LEA; STREET, 1998). Os dados foram gerados por recolha e análise de textos acadêmicos. Eles mostram que a intervenção pedagógica docente resultou na diminuição quantitativa e/ou quantitativa de plágio e no aumento de habilidades de paráfrase e de citação e sugere que $\mathrm{o}$ atendimento das necessidades dos alunos deve ser priorizado independente da abordagem de ensino de escrita adotada.
\end{abstract}

PALAVRAS-CHAVE: Linguística Aplicada. Letramentos acadêmicos. Eventos de letramento. Plágio. Paráfrase.

\begin{abstract}
This case study describes literacy events that took place at a first year subject of a Brazilian undergraduate course on Languages. They include events promoted by professor efforts and those created as a response to student learning needs. Prominent among them was the need to overcome plagiarism as a writing strategy. This paper is based on teaching focused on student needs and on Literacies Approach to writing academic teaching (LEA; STREET, 1998). Data were generated by collection of student pieces of academic writing. Analysis of data shows that teacher educational intervention resulted in development of paraphrasing and using citation abilities and decrease of plagiarism in quantity and/or quality suggesting that responsiveness to students needs should be prioritized regardless of writing learning approach assumed by the teacher.
\end{abstract}

KEYWORDS: Applied Linguistics. Academic literacies. Literacy events. Plagiarism. Paraphrase.

\footnotetext{
* Doutora em Letras pela USP, docente do Programa de Pós-Gradução em Letras, Campus de Cascavel e do Colegiado de Letras, Campus de Marechal Cândido Rondon, Universidade Estadual do Oeste do Paraná (UNIOESTE).
} 


\section{Introdução}

Neste artigo, divulgo resultados de uma experiência educativa realizada com o objetivo de promover eventos de letramentos acadêmicos numa turma de alunos do primeiro ano do curso de Licenciatura em Letras com habilitação dupla (Língua Portuguesa e respectivas literaturas e uma língua estrangeira: Alemão, Espanhol ou Inglês) da Universidade Estadual do Oeste do Paraná, campus de Marechal Cândido Rondon, durante o primeiro semestre de 2015, no decorrer da disciplina de História da Língua Portuguesa, ofertada no primeiro ano do curso. Espero que sua divulgação encoraje outros professores a delinear e implementar estratégias de ensino de escrita acadêmica focadas nas necessidades de aprendizagem de seus alunos.

Ao longo dessa disciplina, vários eventos de letramento foram propiciados aos alunos, tendo em vista os objetivos específicos a serem alcançados, a saber: familiarização com o artigo científico enquanto gênero discursivo situado na disciplina de História da Língua Portuguesa; escrita de resumo de artigo científico; relações de poder e escrita: o ethos do escritor de artigos científicos; leitura e interpretação de artigos científicos; exercícios de escrita dissertativa e escrita de artigo científico baseada em pesquisa bibliográfica. $\mathrm{O}$ objetivo geral de ensino de escrita acadêmica, por sua vez, foi o de incentivar vivências de letramento acadêmico com foco na interpretação e organização de informação com coerência e concisão e utilização das regras de citação, tendo por pressuposto de que outros objetivos cujo alcance é necessário aos letramentos acadêmicos (como, por exemplo, a interpretação crítica, a produção de conhecimento novo, a aplicação de teoria a novos dados ou novas situações, entre outros) poderiam ser focados nos anos subsequentes, especialmente nos terceiro e quarto anos do curso para quando se prevê a elaboração de relatórios de estágio.

Explicitado o ponto de partida da pesquisa, descrevo a organização geral do artigo. Na primeira seção, apresento a fundamentação teórica adotada, na segunda, 
contextualizo e problematizo pesquisas anteriores que tratam do plágio no meio acadêmico e defendo o relacionamento proposto por Swales e Feak (2012) entre plágio e paráfrase. Tendo por pano de fundo esta contextualização geral do assunto, na terceira seção, descrevo o estudo de caso e apresento os resultados obtidos com base na análise de uma seleção de dados gerados durante as aulas da disciplina de História da Língua Portuguesa.

\section{Pressupostos teóricos}

Tanto na configuração quanto na implementação das estratégias de ensino utilizadas ao longo da disciplina, me inspirei na abordagem dos Letramentos Acadêmicos proposta por Lea e Street, em 1998, que as define como práticas sociais cujo domínio, por parte do aluno, requer não somente habilidades e oportunidades de sociabilização, mas também saberes epistemológicos e identitários. São práticas que ocorrem em ambientes institucionais, espaços discursivos permeados por relações de poder. Nesse contexto, o aluno precisa aprender a alternar modos de conhecer e de expressar esse conhecimento de acordo com as práticas vigentes em cada disciplina, as quais podem entrar em conflito com as concepções e crenças prévias (LEA; STREET, 1998, p. 159).

Eventos de letramento, por sua vez, são as ocasiões em que o aluno é instado a fazer uso de práticas de escrita acadêmica, o que quase sempre requer práticas de leitura. Esses eventos podem ser de livre escolha e iniciativa do aluno, como quando ele quer se inscrever no evento com apresentação de comunicação e precisa escrever um resumo para sua inscrição ser aceita ou induzida, como é o caso da intervenção ora relatada que cria uma situação na qual é necessário escrever.

A avaliação formativa realizada ao longo e ao final do processo indicou o desenvolvimento de habilidades de citação e de paráfrase como uma das principais necessidades de aprendizagem dos alunos. A percepção dessa necessidade me 
motivou a elaborar estratégias específicas de ensino cuja fundamentação, testagem e resultados obtidos são descritos a seguir na forma de estudo de caso.

Este retorno ao tema do ensino de habilidades necessárias à escrita acadêmica, contudo, não se baseia na pressuposição de que os alunos são sujeitos com déficits, nem que a eles caberiam a responsabilidade de lidar com o problema por conta própria, mas sim na constatação empírica de que os conceitos que traziam sobre o que era fazer uma pesquisa e colocá-la por escrito eram distintos daqueles consagrados pela academia como adequados à pesquisa científica. Toma-se, como ponto de partida a pressuposição de que habilidades não dominadas, são habilidades não ensinadas, cabendo ao professor a responsabilidade de escolher como objeto de ensino aquilo que aos alunos lhes faz falta.

Cabe aqui mencionar a organização de concepções e crenças sobre a escrita e seu ensino em seis estratos de Ivanič. Cada uma corresponde a uma abordagem de ensino: 1) resultado da utilização de um conjunto de habilidades; 2) processo criativo que serve à autoexpressão do autor; 3) processo de composição que ocorre na mente do escritor; 4) resultado do uso adequado de características peculiares a cada gênero discursivo, este formado por um conjunto de textos típicos; 5) atividade guiada por propósitos comunicativos e socialmente situada; 6) atividade discursiva e sociopoliticamente contextualizada (IVANIČ, 2004, p. 241).

Ivanič defende que um ensino de escrita abrangente deve combinar elementos de todas essas abordagens (IVANIČ, 2004, p. 214) e pondera que, na prática, duas ou mais abordagens podem estar presentes em um módulo didático específico, se bem algumas entrem em conflito, como é o caso da escrita vista como resultado da criatividade do autor e a de escrita concebida como guiada por propósitos comunicativos e pragmáticos. Contudo, tendo em vista o objetivo de maximizar as oportunidades de aprendizagem aos alunos, compartilho sua proposta de "que os professores de escrita podem se beneficiar por estarem conscientes da existência de 
todos os cinco modos de ver a escrita e o ensino da escrita e as práticas pedagógicas associadas com eles, e assim, reconhecer em que discurso(s) de escrita eles habitam"1 (IVANIČ, 2004, p. 242, trad. minha).

O estudo de caso que apresento faz parte de um projeto de pesquisa mais amplo intitulado "Práticas de escrita acadêmica para a formação docente inicial". No projeto, parto de uma concepção de escrita processual, instrumental, interativa e retórica não desvinculada do processo de leitura. Concebo a escrita como processo que requer habilidades cognitivas e linguísticas entre as quais se destacam as interpretativas, uma vez que não separo habilidades de escrita e de leitura por acreditar que não se escreve no vácuo, mas sim a partir daquilo que outros já escreveram, motivo pelo qual a leitura precede a escrita e a escrita se escreve para ser lida, e o próprio escritor escreve o que lê colocando-se no lugar do outro para quem se escreve. Compartilho, pois, com Koch e Elias, da concepção interativa de escrita e de leitura:

a escrita é vista como produção textual, cuja realização exige do produtor a ativação de conhecimentos e a mobilização de várias estratégias. Isso significa dize que o produtor, de forma não linear, "pensa" no que vai escrever e em seu leitor, depois escreve, lê o que escreveu, revê ou reescreve o que julga necessário, em um movimento constante e on-line guiado pelo princípio interacional (KOCH; ELIAS, 2015, p. 34).

os sujeitos são vistos como atores/construtores sociais, sujeitos ativos que - dialogicamente - se constroem e são construídos no texto (...).Nessa perspectiva, o sentido de um texto é construído na interação texto-sujeitos e não algo que preexista a essa interação. A leitura é, pois, uma atividade interativa altamente complexa de produção de sentidos, que se realiza evidentemente com base nos elementos linguísticos (...) e na sua forma de organização, mas requer a mobilização de um vasto conjunto de saberes no interior do evento comunicativo (KOCH; ELIAS, 2014, p. 11).

\footnotetext{
${ }^{1}$ In order to maximise what they offer to learners, I suggest that teachers of writing can benefit from being aware of the existence of all six views of writing and learning to write and the pedagogic practices associated with them, and from recognising which discourse(s) of writing they are inhabiting.
} 
Além de ser interativa, por seu potencial pedagógico, a escrita se presta à produção do conhecimento. Em se tratando do ensino superior, concordo com de Micheli e Iglesia para quem as práticas de escrita devem ser vivenciadas como meios para se chegar à resolução de problemas de pesquisa com os quais os alunos de deparam. Sob este viés, escrever academicamente se torna "uma prática com potencial epistemológico, um recurso de imbatível aprendizagem sistêmica da matéria [que se está estudando]. ${ }^{2}$ (DE MICHELI; IGLESIA, 2012, p. 38, trad. minha)

Tendo isto em vista, antes do início do ano letivo, planejei a transformação da disciplina que ministro na graduação em disciplina de escrita intensiva, sistema de ensino de escrita acadêmica assim descrito por Carlino:

(...) as matérias de escrita intensiva são a adaptação de disciplinas existentes não especificamente destinadas a ensinar a escrever, mas que incorporam um componente redacional e, portanto, modificam seus objetivos, suas metodologias e formas de avaliação para dar lugar ao ensino da escrita, conjuntamente com a transmissão de seus conteúdos disciplinares. $^{3}$ (CARLINO, 2002, p. 1) (trad. minha)

Esse projeto de pesquisa foi apreciado e aprovado pelo comitê de ética em pesquisa ${ }^{4}$, tendo sido seguidas todas as precauções necessárias à integridade dos sujeitos das pesquisas, os quais foram informados sobre o projeto e consentiram em participar. Os alunos assinaram Termo de Livre Consentimento e cederam à pesquisadora os textos produzidos ao longo da disciplina com os quais se iniciou a formação de um banco de dados.

\footnotetext{
${ }^{2}$ We believe that in activities of this kind, writting can became a practice with epistemic potencial, an unbeatable resource in learning the subject from a systemic viewpoint.

3 “(...) las materias de escritura intensiva son la adaptación de asignaturas existentes no específicamente destinadas a enseñar a escribir pero que incorporan un componente redaccional y, por tanto, modifican sus objetivos, metodologías y formas de evaluación para hacer lugar a la enseñanza de la escritura, conjuntamente con la transmisión de sus contenidos disciplinares".

4 A confirmação de aprovação pelo CEP pode ser feita no site da Plataforma Brasil em $<$ http://aplicacao.saude.gov.br/plataformabrasil> pelo número CAAE 48186115.0.0000.0107.
} 
Não obstante terem sido seguidos os procedimentos legais para obtenção da aprovação do Comitê de Ética, sinto necessidade de informar que a pesquisa em tela foi delineada, implementada e avaliada em conformidade com uma epistemologia ética pela qual os alunos não se tornam objetos de pesquisa, mas sim participantes da pesquisa. Assim houve, de minha parte, a tentativa de me despojar de preconceitos e concepções capazes de enviesar a pesquisa e, no limite, denegrir ou prejudicar os participantes.

Este comprometimento ético e político evoca questões que permeiam todo o processo investigativo do delineamento da pesquisa, descrição da metodologia, análise dos dados e divulgação dos resultados, a exemplo de Cavalcanti quando desenvolve pesquisas em Linguística Aplicada que envolvem nações indígenas (CAVALCANTI, 2006).

Ao implementar a pesquisa ora apresentada, pretendi erodir a distinção hierárquica, comum no meio universitário brasileiro, entre pesquisa e ensino. De um lado, minha prática docente e o processo de escrita dos alunos tornaram-se meu objeto de pesquisa, de outro, utilizarei os resultados de pesquisa obtidos como ponto de partida para delineamento de estratégias de ensino que serão utilizadas na próxima oferta da disciplina. Em outras palavras, o ensino virou pesquisa e a pesquisa trará implicações diretas no ensino, numa tentativa de transformar em ação o ideal de entrelaçamento entre ensino e pesquisa proposto por Demo (2011).

Tendo em vista a necessidade de refletir criticamente sobre o fazer docente nas universidades, sinto necessidade de explicitar meu papel enquanto professora universitária e a concepção de aprendizagem que assumo. A este respeito, concordo com o posicionamento de Masseto (2005, p. 82), Zabalza (2004, p. 31) e Copatti e Moreira (2015, p. 130-131). O primeiro estudioso mencionado defende que, no nível superior de ensino, ao aluno deve ser dado um papel central enquanto sujeito ativo a 
quem cabe "buscar as informações, trabalhá-las, produzir um conhecimento, adquirir habilidades, mudar atitudes e adquirir valores (...)" (apud COPATTI; MOREIRA, 2015, p. 130). Com base em Zabalza, para quem é necessário "reforçar a dimensão pedagógica de nossa docência para adaptá-la às condições variáveis de nossos estudantes" (apud COPATTI; MOREIRA, 2015, p. 130), as últimas pesquisadoras mencionadas concluem:

Desse modo, o professor substitui sua função de "transmitir" conhecimentos para a função de "mediador pedagógico" ou orientador no processo de ensino-aprendizagem. A função de ensinar, para o professor universitário, demanda considerar a aprendizagem dos educandos (grifos meus) (COPATTI; MOREIRA, 2015, p. 130-131)

\section{Plágio e paráfrase}

O plágio é um assunto que costuma vir à tona a partir do momento em que se torna alvo de processos jurídicos cujos resultados são amplamente divulgados pela imprensa. Há o caso recente, de 2015, de uma tese em literatura denunciada por plágio que resultou na anulação do título de doutor que havia sido atribuído (CAMARGOS, 2015). Nestes casos, o plágio é visto como um escândalo, produto de um crime que fere os direitos autorais. Desde outro ponto de vista, a ocorrência de plágio nas universidades indica que há necessidade de implementar e divulgar práticas preventivas de plágio, inclusive, nos cursos de licenciatura.

O plágio costuma ser definido como resultado da reprodução de um texto original, na íntegra ou em partes, sem menção à fonte, sendo que esta ausência de marcas leva o leitor do texto a acreditar que a autoria das ideias apresentadas bem como das palavras usadas para expressá-las são do próprio autor do texto. Do ponto de vista jurídico, o plágio resulta numa infração aos direitos autorais, podendo haver penalização daquele que nele incorre. Do ponto de vista moral, o plágio usualmente 
é visto como sinal de desonestidade de quem o faz e desrespeito perante àquele que é plagiado. Neste artigo, o plágio em que incorre os alunos da graduação é visto como uma questão pedagógica e linguística que requer estratégias de ensino não apenas paliativas, mas também preventivas. Ambas as estratégias, por sua vez, estão relacionadas às práticas de escrita acadêmica desenvolvidas no ensino superior, às concepções de escrita e de ensino de escrita do professor e, por fim, às crenças que os alunos têm sobre suas próprias habilidades de escrita.

Sobre a ocorrência de plágio em universidades norte-americanas, os professores Svinicki e Mc Keaschie fazem o seguinte comentário no qual afirmam ser mais difícil combater o plágio quando os alunos vêm de culturas não ocidentais:

A questão do plágio fica cada vez mais complicada à medida que muitos alunos de outros países e culturas "entram nas salas de aula universitárias nos Estados Unidos acreditando que a verdade, a sabedoria e os artefatos culturais, como arte e literatura, são propriedades culturais comunitárias, resultado de anos de sabedoria acumulada transmitida pelos dirigentes venerados e pelas tradições orais, muitas delas religiosas" (SVINICKI; MCKEASCHIE, 2015, p. 243).

Outra crença associada à ocorrência de plágio é a de que seria mais difícil implementar políticas antiplágio, como os códigos de honra utilizados em universidades norte-americanas, em universidades fundadas há menos tempo, que seriam menos robustas, sérias e íntegras conforme evidencia a seguinte ressalva feita por Coughlin em sua pesquisa sobre o plágio em cinco universidades moçambicanas:

Pode haver intensa resistência aos códigos de honra e até mesmo a todo o esforço de detectar e desincentivar o plágio, se muitos docentes e professores catedráticos se formaram em instituições com um ambiente de achismo e elevados índices de fraude acadêmica, como às vezes acontece em países com sistemas universitários em rápida expansão e muitas instituições de ensino superior novas, muitas vezes pequenas e longe de serem robustas (COUGHLIN, 2015, p. 34). 
Da perspectiva que escolho adotar, o plágio ocorre "independente da língua ou da cultura dos estudantes" sempre que houver uma "lacuna nas habilidades acadêmicas dos alunos" especialmente aquelas necessárias à síntese "de uma gama de textos para formar um argumento coerente" ${ }^{5}$ (BRETAG, 2005, p. 2, trad. minha). De acordo com essa pesquisadora australiana, "A maioria dos educadores concordam que o plágio pode ser significativamente reduzido se os estudantes receberem treinamento adequado em letramentos acadêmicos (CHANOCK, 2003; BELL; CUMMING-THOM, 2003; CLEREHAN; JOHNSON, 2003 apud BRETAG, 2005, p. 2).

Considerado um problema compartilhado por toda comunidade acadêmica, Coughlin defende, como solução para a diminuição de plágio entre alunos, a adoção de um "código de honra": uma política antiplágio integrada que abranja várias dimensões desde a publicação e adoção de procedimentos burocráticos para denúncia, julgamento e punição de ocorrências de plágio até a adoção de determinadas ações pedagógicas (COUGHLIN, 2015). Não obstante Coughlin acreditar na eficácia dessas políticas, Svinicki e Mackeachie (2013) e Bretag (2005) ponderam que, nas instituições em que foi adotado, prevalece o viés burocrático, motivo pelo qual os docentes relutam em denunciar alunos plagiadores.

Com relação à dimensão pedagógica dessa política, entre os procedimentos aconselhados por Coughlin (2015), destaco os seguintes:

o enfoque principal deve ser na promoção de competência de redacção e análise, pondo em relevo os benefícios académicos e económicos de técnicas adequadas e de uma boa ética (...) as universidades devem (...) ensinar aos novos estudantes a necessidade e as técnicas para citarem devidamente as fontes (...) Eliminar a confusão didáctica que surge quando as definições e os estilos variam de professor para professor exige uma política uniforme de citações em toda a universidade que permita variações para disciplinas específicas (por exemplo, direito, medicina, engenharia) e, de

\footnotetext{
5 "Other researchers argue that plagiarism occurs when students, redardless of linguistic background, lack the academic skills necessary to synthesis a range of texts into a coherent argument."
} 
preferência, seja reforçada por uma sequência de cursos ou seminários de redacção ao longo do curso de licenciatura (COUGHLIN, 2015, p. 29-30).

Com relação às causas pelas quais os alunos plagiam, Coughlin (2015, p. 25) acredita que "Alguns alunos plagiam por ignorância da ética profissional e técnicas adequadas de citação; outros, para compensar a falta de boas capacidades de pesquisa e de redacção; e outros ainda, devido à pressão de prazos apertados".

Percebi que, para cada uma das causas descritas por Coughlin (2015), Svincki e Mackeachie (2015) propõem estratégias para que o professor universitário possa lidar pedagogicamente com o plágio, conforme se pode observar no quadro 1 a seguir:

Quadro 1 - Correlação entre causas do plágio e estratégias pedagógicas.

\begin{tabular}{|c|c|}
\hline CAUSAS PARA O PLÁGIO & ESTRATÉGIAS PEDAGÓGICAS \\
\hline $\begin{array}{l}\text { Para os alunos não está claro o que se } \\
\text { considera plágio }\end{array}$ & $\begin{array}{l}\text { "(...) deixe claro o que constitui plágio. Diga } \\
\text { aos alunos quais são os documentos } \\
\text { necessários para os trabalhos, incluindo o uso } \\
\text { da internet. Informe-lhes o que é colaboração } \\
\text { aceitável e o que é inaceitável" (SVINCKI; } \\
\text { MCKEACHIE, 2015, p. 244). }\end{array}$ \\
\hline $\begin{array}{l}\text { Os alunos não dominam técnicas adequadas } \\
\text { de citação }\end{array}$ & $\begin{array}{l}\text { "Incentive os alunos a conversar (ou mandar } \\
\text { e-mail) se tiverem dúvidas sobre as citações. } \\
\text { Tente convencê-los de que admitir que não } \\
\text { sabem algo é muito melhor do que cometer } \\
\text { erros que podem constituir plágio" } \\
\text { (SVINCKI; MCKEACHIE, 2015, p. 244). }\end{array}$ \\
\hline $\begin{array}{l}\text { Aos alunos, lhes falta tempo para cumprir } \\
\text { com os prazos para entrega dos trabalhos }\end{array}$ & $\begin{array}{l}\text { "Peça aos alunos que verifiquem o programa } \\
\text { e o cronograma de estudos (...) permita que os } \\
\text { alunos entreguem um trabalho com } \\
\text { antecedência (...) ou [com] um atraso na } \\
\text { entrega". (SVINCKI; MCKEACHIE, 2015, p. } \\
244)\end{array}$ \\
\hline $\begin{array}{l}\text { Os alunos ignoram a ética, sendo, por isso } \\
\text { desonestos }\end{array}$ & $\begin{array}{l}\text { Elabore "normas de grupo que apóiam a } \\
\text { honestidade.(...) Um debate sobre a } \\
\text { desonestidade acadêmica é útil para ajudar os } \\
\text { alunos a reconhecer que colar é ruim" } \\
\text { (SVINCKI; MCKEACHIE, 2015, p. 103) }\end{array}$ \\
\hline
\end{tabular}

Fonte: Elaborado pelo autora. 
Apesar de úteis e eficazes, as sugestões de Mackeachie e Svincki (2015) e Coughlin (2015) podem não ser suficientes, caso o plágio ocorra devido ao aluno ainda não dominar plenamente habilidades de uso linguístico que o capacitariam a se expressar de próprio punho: a capacidade de parafrasear textos. A ideia de que plágio e paráfrase estão relacionados é defendida por Swales e Feak (2012). Para eles, “Uma paráfrase é uma reformulação (nas suas próprias palavras) das ideias de um [texto] original. Uma boa paráfrase pode demonstrar que você entendeu mesmo o texto que você leu e é capaz de evitar o plágio" ${ }^{6}$ (SWALES; FEAK, 2012, p. 202, trad. minha)

Para a paráfrase ser realmente fidedigna ao texto original, o primeiro requisito é que o escritor identifique, contextualize e interprete as ideias do texto a ser parafraseado; o segundo, que se escolham adequadamente os sinônimos que podem ser utilizados (SWALES; FEAK 2012, p. 206); o terceiro que se saiba que, quando se trata de termos (itens lexicais ou expressões plurilexicais utilizados numa linguagem especializadas para expressar um conceito), é aconselhável que não sejam substituídos por outros itens (SWALES; FEAK 2012, p. 208); por fim, é preciso saber utilizar as normas adotadas para citações longas e curtas, de primeira ou segunda mão.

Além disso, para a avaliação das produções escritas dos estudantes, é necessário verificar se o texto é coerente, isto é, se as frases que compõem o texto apresentam em conjunto: articulação, continuidade, informatividade, não contradição e progressão (COSTA VAL, 1993) e, também, se não há falhas de coesão nesse conjunto, entendendo por coesão o resultado do uso de recursos sintáticos e semânticos como a concordância verbal, a concordância nominal e o uso de conectivos.

No estudo de caso que descrevo a seguir, parti do pressuposto de relação entre plágio e paráfrase defendido por Swales e Feak (2012), os resultados desta

\footnotetext{
6 "A paraphrase is a restatement (in your own words) of the ideas in the original. Good paraphrasing can demonstrate that you have understood the text you have read and can avoid plagiarizing".
} 
experiência educativa, por sua vez, levaram em consideração os estudos anteriores brevemente descritos na seção precedente. Ressalvo que a análise que faço a seguir recobre apenas uma parte dos dados gerados por uma seleção de sujeitos que foram escolhidos entre os participantes da pesquisa.

\section{Descrição do estudo de caso e resultados obtidos}

O estudo de caso teve início com o procedimento de elaboração do plano de ensino da disciplina de História da Língua Portuguesa no qual foram incluídas estratégias de familiarização com o artigo científico da área de Linguística Histórica e ensino de escrita. Foram previstas as seguintes atividades: a) leitura e a análise de seis artigos acadêmicos; b) seis exercícios de fornecer reposta dissertativa a questão sobre os artigos lidos; c) exercício de elaboração de resumo para um artigo científico; d) elaboração, em grupos, de um artigo científico cujo tema era escolhido a partir de um elenco de cinco sugestões; e) reunião presencial com os grupos para orientação visando a elaboração de uma segunda versão; e) refacção do artigo com base nas orientações dadas.

Após a primeira entrega de questionário dissertativo, escolhi uma resposta mediana, uma resposta boa e uma resposta inadequada para apresentação e discussão em sala de aula, sem divulgar os nomes de seus autores. Devo informar que, na última resposta, houve muitos trechos plagiados. Durante a avaliação dessa resposta, realcei em amarelo as partes plagiadas e, após mostrar as ocorrências de plágio no texto, entreguei aos alunos um roteiro para avaliação de respostas dissertativas.

$\mathrm{Na}$ aula seguinte, usando o roteiro, os alunos foram motivados a conversarem comigo e me dizerem que nota acreditavam terem tirado. Quase todos acertaram na descrição de falhas e virtudes de seus próprios textos e concordaram com a nota atribuída. 
A avaliação da segunda entrega de questionário dissertativo mostrou progresso no aperfeiçoamento das habilidades escritas dos alunos, porém, ao avaliar os textos produzidos para a terceira entrega, notei que houve uma piora na qualidade dos textos e mais ocorrência de plágio, o que me motivou a elaborar, como estratégia de ensino complementar, exercícios focando recursos sintáticos para elaboração de paráfrases com base em um dos exercícios propostos por Swales e Feak (2012, p. 204). Nesses exercícios, utilizei trechos de artigos brasileiros e de textos escritos pelos próprios alunos.

Após esse exercício, uma leva de dez alunos ingressou no curso pelo sistema SISU para ocupação de vagas remanescentes na habilitação Língua PortuguesaLíngua Alemã, até então, o curso contava com 37 alunos matriculados. A esta altura do curso, esses alunos não teriam condições de entregar os questionários já solicitados. Considerando a situação desses alunos e também aqueles que não tinham conseguido entregar todos os trabalhos ou cujos trabalhos não estavam adequados, elaborei um trabalho de recuperação com o mesmo valor e um prazo mais longo de entrega e avisei a todos que prevaleceria a nota maior.

Após entrega da primeira versão do artigo, os grupos foram orientados por mim. Todos os grupos apresentaram algum grau de plágio: desde citação de fonte secundária como se fosse primária até reprodução de artigo na íntegra (um trabalho individual), reprodução de parte de um artigo e parte de outro (um trabalho individual) e mescla de trechos de dois ou mais artigos sem qualquer menção aos autores (um grupo formado por quatro componentes).

Após orientação individualizada visando a ajustes necessários à segunda versão dos artigos, um dos alunos que havia plagiado não entregou segunda versão e também não mais assistiu às aulas, o grupo de quatro componentes apresentou um artigo diferente do anterior, porém, com as mesmas falhas do primeiro e o outro aluno que também fez trabalho individual conseguiu aperfeiçoar um pouco o texto, 
se bem que minimamente. Nos demais grupos, houve diminuição significativa de plágio e aperfeiçoamento substancial dos artigos.

Após a matrícula dos que chegaram por último e subtração daqueles que desistiram do curso, a turma ficou com um total de 38 alunos efetivos. Todos os alunos receberam orientações durante as aulas, leram e interpretaram exemplares do gênero discursivo em tela, realizaram exercícios de escrita, esboçaram uma primeira versão de artigo e elaboraram a versão final dos artigos segundo orientação que lhes dei pessoalmente, grupo a grupo. Essas atividades foram suficientes para que o grupo majoritário, formado por 28 alunos $(86,45 \%)$, desenvolvesse as habilidades necessárias à superação do uso de paráfrase como estratégia de escrita. Contudo, 05 alunos (13,15\% do total) não conseguiram evitar o plágio, mesmo após receberem orientação individual.

O grupo minoritário não participou de todas as atividades de que participou o grupo majoritário. Esses alunos foram chamados à matrícula quase dois meses após o início do semestre para ocupar vagas remanescentes. Uma explicação fácil para o desempenho insatisfatório deles alunos seria acreditar que eles seriam menos aptos ao ensino superior por terem sido chamados à matrícula por último, pelo sistema SISU, na habilitação dupla menos concorrida do curso, a de Português-Alemão, não tendo havido, portanto, "a escolha dos melhores".

A análise do desempenho desses alunos em exercícios de paráfrase antes das aulas de preparação para o exame final e no exame final, contudo, corrobora ser o plágio uma questão, antes de tudo, pedagógica. Para mensurar o plágio nessas atividades, pautei-me na noção gradual de plágio presente num dos exercícios elaborados por Swales e Feak (2012, p. 198).

Num extremo, há o grau máximo de plágio, no qual há “cópia de um parágrafo exatamente igual à fonte utilizada, mas sem mencioná-la ${ }^{7 \prime \prime}$ (que eu chamo de grau 3.)

7 "Copying a paragraph as it is from the source without any acknowledgment". 
Indício que houve alguma tentativa de paráfrase é o plágio no qual há cópia de um parágrafo, porém com poucas e "pequenas mudanças, como substituir alguns verbos ou adjetivos por sinônimos" ${ }^{8}$ (que eu chamo de grau 2). Diminuindo a gravidade do plágio, no grau seguinte, há a tentativa de parafrasear ou modificar algumas frases, há "recorte e cópia de um parágrafo usando as orações do texto original, mas deixando uma ou duas de fora ou mudando a ordem das palavras de uma ou duas frases ${ }^{9 \prime \prime}$ (que eu chamo de grau 1). O plágio deixa de existir quando a reescrita do parágrafo fonte ocorre "com mudanças substanciais na linguagem utilizada e na organização do parágrafo, na quantidade de detalhes e de exemplos" (grau 0). Também levei em consideração, a qualidade da paráfrase, isto é, se havia fidedignidade às ideias do texto original e os fatores de textualidade do texto produzido pelo aluno.

O exercício de paráfrase anterior à preparação ao exame final consistiu num trabalho avaliativo (o trabalho de recuperação já mencionado) realizado fora da sala de aula. Para esse trabalho, selecionei quatro trechos de quatro artigos diferentes que foram objeto de leitura e estudo durante as aulas e solicitei aos alunos uma paráfrase de cada um e também a elaboração de uma pergunta cuja resposta poderia ser encontrada nas informações do texto. Elaborei essa última atividade para ter mais indícios sobre o nível de leitura e interpretação textual dos alunos. Para o exame final, por sua vez, na última aula de preparação, informei aos alunos que artigo "cairia" no exame. Após uma semana de recesso, os alunos fizeram o exame no qual solicitei paráfrase de um dos trechos do artigo.

A avaliação diagnóstica do trabalho avaliativo e da segunda versão do artigo mostrou-me as seguintes necessidades de aprendizagem desses alunos: instruções sobre como fazer citação de fonte primária e fonte secundária nos textos,

\footnotetext{
8 "Copying a paragraph making only small changes, such as replacing a few verbs or adjectives with synonyms".

9 "Cutting and pasting a paragraph by using the sentences of the original but leaving one or two out, or by putting one or two sentences in a different order".
} 
conhecimento de que termos não podem ser substituídos por sinônimos, percepção de que sinônimos mal escolhidos podem modificar as ideias do texto original e/ou revelar que houve má interpretação dele, concepção do que é plágio e de que existem graus variados de plágio.

Para dar conta dessas necessidades, realizei as seguintes ações pedagógicas. Na primeira aula de preparação para o exame final, forneci material impresso com a tradução que elaborei da tarefa 3 do livro de Swales e Feak (2012, p. 198) e pedi aos alunos que a fizessem. Feito o exercício, ele foi corrigido e comentado. $\mathrm{Na}$ sequência, apliquei um exercício por mim criado com trechos extraídos dos artigos em que havia paráfrases com graus diferentes de plágio, sinônimos mal escolhidos e deturpação das ideias do texto original. Após avaliação dos trechos pelos alunos e comentários meus sobre a avaliação feita por eles, indiquei, como tarefa, as seguintes atividades: 1) escolha de um trecho de um dos artigos, 2) cópia manuscrita do trecho escolhido numa folha de papel, 3) elaboração de paráfrase do trecho em outra folha. Essa tarefa me foi entregue na aula seguinte. Na segunda aula, um aluno avaliou a paráfrase do outro e individualmente, eu avaliei a avaliação do aluno e complementei a análise feita. A ao final da aula, os textos foram devolvidos a cada um e informei que artigo os alunos deveriam ler e estudar previamente para o exame final.

O primeiro trecho da primeira paráfrase solicitada no trabalho de recuperação e o primeiro trecho da paráfrase do exame final de cada sujeito foram cotejados, comparação visualizada nos quadros 2 a 6 reproduzidos a seguir. Nesses quadros, a análise das paráfrases do foi por mim realizada e evidenciada mediante utilização de marcações no texto do aluno. Coloquei com fonte sublinhada as partes nas quais houve plágio ipsis literis. Os trechos parafraseados permaneceram com fonte normal. Coloquei em caixa alta as tentativas de paráfrase que resultaram em deturpação das ideias do texto original. Acrescentei um sinal de asterisco para indicar trechos nos 
quase houve comprometimento de algum fator de textualidade. Após cada quadro, há a análise dos dados e respectivos resultados. Enquanto, no quadro 2, apresento os textos originais, nos demais quadros, omitem-se os textos para evitar repetições.

Quadro 2 - Comparação de trechos iniciais de 2 paráfrases escritas pelo aluno 1.

\begin{tabular}{|c|c|}
\hline $\begin{array}{l}\text { Trecho original do trabalho avaliativo } \\
\text { Conforme visto, os sufixos estudados tiveram a } \\
\text { sua origem na língua grega, adentraram o } \\
\text { latim e, por meio dessa língua, as línguas } \\
\text { românicas. Entretanto, somente a partir do } \\
\text { século XVIII começaram a ter produtividade } \\
\text { própria nas românicas, devido à sua } \\
\text { propagação pelo latim científico, no âmbito } \\
\text { técnico e acadêmico, mas também em outros } \\
\text { âmbitos por influência de línguas de cultura, } \\
\text { tais como o francês, italiano e alemão, dentre } \\
\text { outras (AREÁN; GARCÍA, 2013, p. 452) }\end{array}$ & $\begin{array}{l}\text { Trecho original do exame final } \\
\text { (...) alguns estudiosos levantam a possibilidade } \\
\text { de que Afonso X teria sido falante nativo de } \\
\text { galego-português. Filgueira Valverde (1985, p. } \\
\text { XI) considera essa não uma possibilidade, mas } \\
\text { uma certeza (...)Esse autor (FILGUEIRA } \\
\text { VALVERDE, 1985, p. XIV) dá a extensão dessa } \\
\text { estadia de Afonso X na Galiza durante a } \\
\text { infância: de } 1223 \text { a } 1231 \text { - não-desprezíveis nove } \\
\text { anos, bem na fase de aquisição da língua } \\
\text { materna (dos dois aos onze anos).(...) (MASSINI; } \\
\text { CAGLIARI, 2011, p. } 805)\end{array}$ \\
\hline $\begin{array}{l}\text { Paráfrase } 1 \text { do aluno } 1 \\
\text { Os sufixos estudados se originaram da língua } \\
\text { grega e posteriormente através do latim nas } \\
\text { línguas românicas. Contudo A PRODUÇÃO } \\
\text { PRÓPRIA ROMÂNICA iniciou-se no século } \\
\text { XVIII, devido a propagação do latim científico } \\
\text { através do âmbito técnico, acadêmico, } \\
\text { INTERFERÊNCIAS LINGUÍSTICAS (francês, } \\
\text { italiano, alemão, etc.) E CULTURAIS. }\end{array}$ & 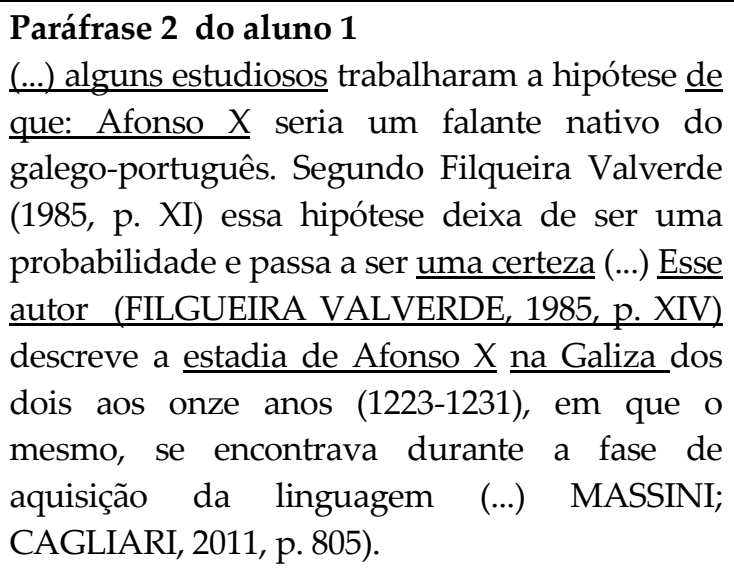 \\
\hline
\end{tabular}

Fonte: elaborado pela autora.

Comparando as paráfrases do aluno 1, percebo que, no primeiro texto, as tentativas de substituição de palavras e expressões do texto original por sinônimos abrangeram termos da morfologia, resultando em deturpação dos conceitos utilizados por Areán-Garcia, conforme indicam as palavras que coloquei em caixa alta. Segundo indica a ausência de palavras em caixa alta no segundo texto, a realização das atividades de preparação ao exame parece que conscientizou o aluno para a necessidade de ser fidedigno ao texto. Não se pode negar que o aluno 1 avançou no processo de aprendizagem das habilidades necessárias à escrita de 
paráfrase, mesmo considerando que, no segundo texto, ainda há reprodução ipsis literis do original, que em nenhum dos trechos há referências ao autor do autor original, e que, no segundo, não se informa ser secundária a utilização de Filgueira Valverde. Um avanço de outra natureza também foi obtido pelo aluno 2 cujos trechos de escrita reproduzi no quadro 3 a seguir.

Quadro 3 - Comparação de trechos iniciais de 2 paráfrases escritas pelo aluno 2.

Paráfrase 1 do aluno 2
Os sufixos tiveram origem da língua grega,
seguido do latim* e por fim as românicas. Mas
$\frac{\text { somente a partir do sec. XVIII, começaram AS }}{\text { PRODUTIVIDADES NA NGUA }}$
ROMÂNICA, por causa do desenvolvimento
do latim científico, PRINCIPALMENTE na
esfera técnica e acadêmica. Já em outras
esferas outras línguas de cultura tiveram suas
influências como o francês, italiano e alemão.

Paráfrase 2 do aluno 2
Estudos analisados informam que Afonso X,
provavelmente NASCEU COM O DOMÍNIO
DA LÍNGUA GALEGA-PORTUGUÊS, ou
seja, tornando-a sua LÍNGUA DE ORIGEM.
Torna-se afirmativa a questão analisada
acima*, segundo o estudioso Figueira
Valverde.

Fonte: elaborado pela autora.

Noto que, na primeira paráfrase do aluno 2, além dos trechos reproduzidos ao pé da letra, há deturpação das ideias originais e um trecho com falhas coesivas. A não percepção de que não é aconselhável substituir termo por sinônimos resultou, também na paráfrase 2, em corrupção dos conceitos do texto original. Além disso, parece terem permanecido falhas de textualidade: enquanto, no texto 1, a falha era de coesão, no texto 2 , há uma falha de textualidade quando se faz referência uma questão que não foi cogitada no texto. Assim como nos trechos do aluno 1, não se faz menção aos autores parafraseados, nem ao fato de Figueira Valverde ser uma fonte secundária. Não obstante essas debilidades, noto que não houve reprodução ipsis literis no segundo texto, o que representa um avanço no processo de aprendizagem. Percebi outro tipo de avanço na escrita do aluno 3 cujos trechos são visualizados a seguir. 
Quadro 4 - Comparação de trechos iniciais de 2 paráfrases escritas pelo aluno 3.

\section{Paráfrase 1 do aluno 3}

Os sufixos originam-se na língua grega, posteriormente a isso são INSERIDOS DENTRO DO LATIM e por meio desta*, as línguas românicas, contudo, a partir do século XVIII propagou-se pelo latim científico*, no âmbito técnico e acadêmico e AINDA SOFREU INFLUENCIA DE LÍNGUAS DE CULTURA, TAIS COMO A FRANCESA, ITALIANA E ALEMÃ.

\section{Paráfrase 2 do aluno 3}

Quando criança Afonso $X$ viveu durante nove anos na região da Galiza, MEADOS DE 1223 a 1231.Este período foi muito importante para sua formação, pois ao longo dos anos aprendeu a falar a língua típica daquela região o galego-português.

Fonte: elaborado pela autora.

Apesar de, assim como nos trechos já analisados, nesse também não haver menção às fontes utilizadas nas paráfrases, observo que há progressos visíveis no processo de aprendizagem de escrita de paráfrase: no segundo trecho não há falhas de textualidade. Além disso, ainda que tenha havido supressão de informação, há menos deturpação dos conceitos. No trecho 2, a palavra colocada em caixa alta modifica a informação factual fornecida, trata-se, contudo, de uma inadequação vocabular e não de uma tentativa de substituir um termo por um sinônimo. Avanços semelhantes observei na escrita do aluno 4 cujos trechos estão visualizados no quadro 5.

Quadro 5 - Comparação de trechos iniciais de 2 paráfrases escritas pelo aluno 4 .

\section{Paráfrase 1 do aluno 4}

Após a origem dos sufixos, na língua grega, adentrou- $\mathrm{o}^{*}$ ao* latim, e, por fim, às línguas românicas. Devido às diversidades do trajeto, somente a partir do século XVIII deram-se início a sua própria constelação nas línguas românicas, devido à irradiação no Latim científico, no âmbito técnico e acadêmico e, também, $a^{*}$ influência DE DIVERSAS CULTURAS, como, por exemplo: francesa, italiana, alemã, entre outras.

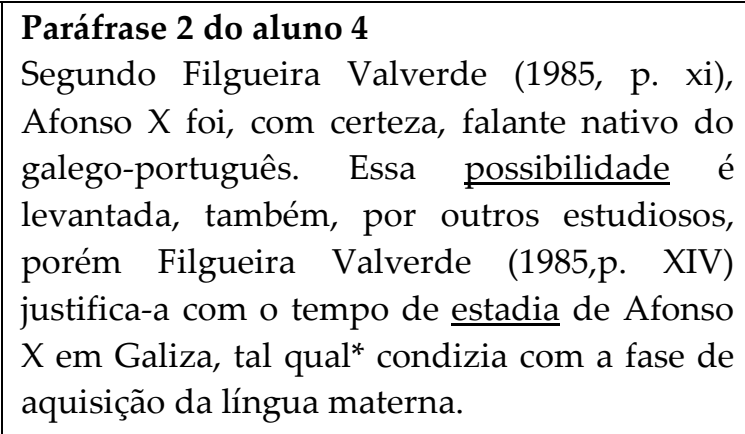
Afonso $\mathrm{X}$ foi, com certeza, falante nativo do galego-português. Essa possibilidade é levantada, também, por outros estudiosos, porém Filgueira Valverde (1985,p. XIV) justifica-a com o tempo de estadia de Afonso $X$ em Galiza, tal qual ${ }^{*}$ condizia com a fase de aquisição da língua materna.

\section{Fonte: elaborado pela autora.}

No primeiro trecho, não há menção às fontes, contudo, percebo ter havido progresso: no segundo trecho, não há problemas coesivos como no primeiro, há 
menos reprodução literal e não há deturpação de conceitos ou ideias. Além disso, a análise dos trechos escritos pelo aluno 5 evidencia ter havido progresso na aprendizagem de citação de fontes: há citação a Valverde.

Quadro 6 - Comparação de trechos iniciais de 2 paráfrases escritas pelo aluno 5.

\begin{tabular}{|c|c|}
\hline Paráfrase 1 do aluno 5 & Paráfrase 2 do aluno 5 \\
\hline Os sufixos que foram estudas* se originaram & dos pesqu \\
\hline na língua & possibilidade que Afonso \\
\hline FORMULA DESSA LÍNGUA, & ativo falante \\
\hline $\begin{array}{l}\text { línguas românticas*, mas foi somente a partir } \\
\text { do século XVIII que começaram A TER }\end{array}$ & $\begin{array}{l}\text { Valverde }(1985, \text { p. xi) considera isso uma } \\
\text { certeza e não apenas uma eventual }\end{array}$ \\
\hline RENDIMENTO CARACTERÍSTICO NAS & possibilidade $\quad(. .)$. \\
\hline $\begin{array}{l}\text { ROMÂNTICAS, em virtude de sua } \\
\text { propagacão pelo latim cientifico, VISTO PELO }\end{array}$ & $\begin{array}{l}\text { VALVERDE, 1985, p. xiv) nos mostra o } \\
\text { tamanho* do período de Afonso X na Galiza }\end{array}$ \\
\hline $\begin{array}{llr}\text { PLANO técnico e acadêmico, do mesmo } \\
\text { modo em outros contextos, }\end{array}$ & $\begin{array}{l}\text { em sua infância: de } 1223 \text { a } 1231 \text { - não } \\
\text { menosprezando* nove anos, sendo } \mathrm{O}\end{array}$ \\
\hline INTERVE & MOMENTO DE \\
\hline cul & dois aos onze a \\
\hline entre ou & $\begin{array}{l}\text { MASSINI; CABLIARI, 2011, p. 805) (...) (apud } \\
\text { MASSINI; CAGLIARI, 2011, p. 805) }\end{array}$ \\
\hline
\end{tabular}

Fonte: elaborado pela autora.

Ao comparar os trechos escritos pelo aluno 5, verifico que suas habilidades progrediram bastante, se bem que, em ambos os textos, haja falhas de textualidade. Focando o progresso do aluno, observo que os conceitos foram menos deturpados (enquanto há quatro ocorrências no trecho 1, há apenas 1 no trecho dois) e há menos reprodução do original. Chama também a atenção o fato de o aluno ter citado a fonte utilizada ao final do segundo trecho e ter tentado usar o recurso ao apud, o que indica a utilização de uma fonte secundária, ainda que a lembrança dessa necessidade tenha surgido apenas ao final de todo o texto escrito pelo aluno.

De maneira diferente e em graus variados, a análise comparativa que fiz dos trechos iniciais das paráfrases escritas antes e depois da preparação para o exame final pelos cinco alunos mostra que todos progrediram rumo ao domínio das habilidades necessárias para, fazendo boas paráfrases e utilizando adequadamente os recursos de citação, evitarem o plágio como estratégia de escrita. 
Esses são dados que mostram as vantagens de se lidar com o plágio tratando-o como uma questão essencialmente pedagógica: o plágio deixa de ser uma questão atrelada às crenças do corpo docente sobre as capacidades linguísticas e as características culturais dos alunos ou como uma questão burocrática, jurídica, que requer penalização, e aos alunos são dadas as condições para a superação do plágio como estratégia de escrita de textos acadêmicos.

Este estudo de caso mostra que vale a pena dar a atenção pedagógica necessária para o desenvolvimento dos letramentos dos alunos levando em consideração as suas necessidades. Quando se trata de cursos de formação de professores, isto é ainda mais urgente, tendo em vista que um professor que se forma acreditando que a atividade de pesquisas não equivale à mera compilação e reprodução de um ou mais textos estará mais atento para esta questão quando solicitar atividades de pesquisa de seus alunos, o que pode criar um ciclo virtuoso com alunos chegando às universidades com habilidades de pesquisa e de escrita mais desenvolvidas.

\section{Considerações Finais}

A disciplina de História de Língua Portuguesa foi planejada para se tornar uma disciplina de escrita intensiva, com um ensino de escrita embasada na abordagem dos letramentos acadêmicos e uma concepção geral de ensino pautada nas necessidades dos alunos. A avaliação formativa realizada no decorrer das aulas, contudo, revelou que uma das principais necessidades dos alunos está no desenvolvimento de habilidades de paráfrase e de citação.

As mudanças que implementei para ir ao encontro do que necessitavam os alunos surtiram resultado: houve avanços no desenvolvimento de habilidades de paráfrase e citação por parte de todos os 38 alunos da disciplina de História da Língua Portuguesa. 
Esses resultados podem ser analisados se modo mais amplo ou mais específico. Especificamente, eles evidenciam que, nos cursos de graduação em geral, e, especialmente, nas licenciaturas, é preferível lidar com o plágio pedagogicamente, para tanto, é preciso que os professores ensinem como parafrasear, mostrando o que é considerado plágio e propondo atividades que desenvolvam o que os alunos precisam saber para superar suas dificuldades.

De um ponto de vista mais amplo, eles indicam que, talvez mais importante que a(s) abordagem(ns) adotada(s) pelo professor para o ensino de escrita acadêmica, seja sua atitude perante a aprendizagem dos alunos a cujas necessidades é necessário estar atento. Igualmente fundamental é a atitude docente perante os erros dos alunos. É preciso ser, ao mesmo tempo, otimista e realista. É preciso acreditar que a atenção pedagógica dada ao assunto surtirá resultados, que vale a pena apostar no aluno.

Quando parece haver persistência no erro, é igualmente necessário não desconsiderar o princípio de incerteza que permeia todo processo de aprendizagem: não se pode perder de vista que, como alerta Lewis,

Aulas bem planejadas e inclusive bem realizadas não garantem um bom aprendizado. Aceitar a incerteza como parte de seus princípios, fará com que o professor tenha uma atitude mais paciente e tolerante perante os problemas dos alunos, e também o desejo de auxiliá-los em seus esforços para conseguir aprender ${ }^{10}$ (LEWIS, 1993, p. 33-34, trad. minha)

\section{Referências}

ARÉAN-GARCIA, N. Trajetória da constelação sufixal:- imo, - ista, -ístico (a) e ística - desde a origem grega às línguas modernas. Estudos Linguísticos, 42 (1), p. 442-454,

\footnotetext{
10 "Well-planned, and even well executed lessons cannot guarantee good learning. Accepting uncertainty as part ofyour mind-set develops patience, tolerance of learner's problems, a willingness to support them as they strugglewith the learning process".
} 
jan-abr.2013. Disponível em: $\underline{\text { https://revistas.gel.org.br/estudos- }}$ linguisticos/article/viewFile/979/565. Acesso em: 29 ago 2016.

BRETAG, T. Implementing plagiarism policy in the internationalized university, 2005. Disponível em: https://www.researchgate.net/publication/228675234. Acesso em: 10 ago 2016.

CAMARGOS, D. UFMG cassa diploma de doutorado de professora por plágio. Disponível

em: https://www.em.com.br/app/noticia/gerais/2015/10/27/interna gerais,701989/ufmgcassa-diploma-de-doutorado-de-professora-por-plagio.shtml. Acesso em 10 out. 2016.

CARLINO,P. Enseñar a escribir en todas las materias: como hacerlo en la universidad. In: Seminario Internacional de Inauguración Subsede Cátedra UNESCO. Lectura y escritura: nuevos desafíos, 2002. Mendoza, Argentina: Facultad de Educación Nacional de Cuyo, Mendoza, 6 de abril de 2002, p. 1-6.

CAVALCANTI, M. C. Um olhar metateórico e metametodológico em pesquisa em Linguística Aplicada: implicações éticas e políticas. In: MOITA-LOPES (org.) Por uma Linguística Aplicada Indisciplinar. São Paulo: Ed. Parábola. 2006. p. 231-252.

COPATTI, C.; MOREIRA, D. O. A formação estética para a construção do sensível na docência universitária. In: FÁVERO, A. A.; TONIETO, C.; ODY L. C. (orgs.). Docência Universitária: pressupostos teóricos e perspectivas didáticas. Campinas: Mercado de Letras, 2015, p. 121-147.

COSTA VAL, M. G. Redação e textualidade. São Paulo: Martins Fontes, 1993.

COUGHLIN, P. Plágio em Cinco Universidades de Moçambique: Amplitude, Técnicas de Detecção e Medidas de Controlo. Cadernos IESE, Maputo, Moçambique no.15, 2015. Disponível em: http://www.iese.ac.mz. Acesso em: 10 ago 2016.

DE MICHELI, A.; IGLESIA, P. Writing to learn biology in the framework of a didactic-curricular change in the first year program at an argentine university. In: THAISS, C. et. al. (orgs.) Writing Programs Worldwide. The WAC Clearinghouse South Carolina, USA, 2012, p. 35-42.

DEMO, P. Pesquisa: princípio científico e educativo. 14. ed. São Paulo: Cortez, 2011, 120 . 
IVANIČ, R. Discourses of writing and learning to write. Language and education. v. 18, n. 3, p. 220-245, março, 2004. Disponível em: http://www.tandfonline.com/toc/rlae20/18/3?nav=tocList. Acesso em: 06 fev 2017.

LEA, M.; M.; STREET, B. V. Student Writing in Higher Education: an academic literacies approach. Studies in Higher Education, vol.23, no.2, p.175-172. Acesso em: 10 jan 2017. http://dx.doi.org/10.1080/03075079812331380364

LEWIS, M. The Lexical Approach. The State of ELT and a Way Forward. Londres: Language Teaching Publications, 1993, 330p.

MASSINI-CAGLIARI, G. Adaptação fonológica de nomes próprios de origem estrangeira: comparação entre Português Arcaico e Português Brasileiro. Estudos Linguísticos, São Paulo, 40 (20), p. 795-807, mai-ago 2011. Disponível em: https://revistas.gel.org.br/estudos-linguisticos/article/download/.../883. Acesso em: 29 ago 2016.

MCGOWAN, U. Plagiarism detection and prevention: are we putting the cart before the horse? Higher Education In a Changing World, p. 287-293. 2005. Disp. em https://www.researchgate.net/publication/228339483 Plagiarism detection and pre vention Are we putting the cart before the horse.Acesso em: 29 ago 2016. 